\title{
Analysis on the erosion and side exchange of pipeline in the whole life cycle
}

\author{
Xinzhuo Zhang ${ }^{1,}$, , Ting Xiong ${ }^{1, ~ b, ~}{ }^{*}$, Mengda Zhang ${ }^{1, c}$ and Zhenping $\mathrm{Li}^{2, \mathrm{~d}}$
}

${ }^{1}$ School of energy and power engineering, Wuhan University of Technology, Wuhan 430063, China.

${ }^{2}$ Ship Inspection Institution of Wuhan, Wuhan 430030, China.

a1227822082@qq.com, bbearmos@163.com, czhangmd1012@foxmail.com, dzp0327@163.com

Keywords: Fluid force, erosion, Wall erosion.

\begin{abstract}
The erosion is one of the main reasons of material destruction and equipment failure. This paper presents a numerical study of horizontal pipe erosion by the approach of computational fluid dynamics (CFD). Take the typical structure of horizontal pipe as the research object, using the standard $\kappa-\varepsilon$ turbulence model and erosion wear model to get wall erosion ratio for numerical calculation. And then the worn pipe model can be built based on the value. Research shows that in the cases of different shapes of cross-section of the pipe which is caused by erosion, the location of the wear area and the value of the erosion ratio are basically the same. The maximum erosion ratio appeared at the lower part of the inner wall of pipeline, and the erosion area was fan-shaped symmetrically located at the lower part of the inner wall of pipeline. According to the distribution characteristic, the side exchange was offered, which could enhance the service life of the pipeline by times.
\end{abstract}

\section{Introduction}

Erosion is a very common material loss in industrial production. Wear is one of the most common forms of pipe failure. At the beginning of the 1960s, the study of the erosive wear loss of solid particles on equipment's such as pipelines began in Europe, and scholars in Europe and the United States began to pay attention to the erosion problem of pipelines and did a lot of research in this field. J. Postleewwait, Rydberg [1] et al. analyzed the influence of flow pattern on erosion. Chen [2] et al. used CFD method to research the erosion wear of gas-solid two-phase flow on the three-way tube and elbow through numerical simulation, Lee [3] et al. studied the erosion of boiler pipe through numerical simulation based on Fluent. Oka Y I [4] [5] changed the important parameters by the experiments to research the law of the erosion wear and put forward the erosion wear prediction equation. In China, Zhang Y and others [6], respectively, used the two methods of experimental research and numerical calculation to study erosion wear. Sun Haijiang and Ou Guofu [7] et al. studied the erosion for $90^{\circ}$ circular cross section of multiphase flow elbow in coal liquefaction by numerical investigation. FU Lin and Gao Bingjun [7] used the Fluent software to simulate the influence of the diameter and bending ratio of the elbow on the erosion and the wear. Zhang Shaofeng and Cao Huimin et al. [9] studied the erosion and wear of the solid-liquid two-phase flow in the elbow, and Ma Ying [10] explained the essence of erosion and wear, summarized the erosion theory and studied the influence of some main factors on erosion wear through the research. Mao Jingru et al. [11] studied the secondary flow of gas-solid two-phase in $90^{\circ}$ square cross-section elbow.

Solid-liquid two-phase transported in the pipeline is bound to consume energy, part of the energy used to overcome the transport area ups and downs of the terrain, the more is used to overcome the friction caused by the slurry transported in the pipeline. At present, a lot of research has been done to study the mechanism of erosion and wear, the protective measures and the anti-erosive wear material, and the research has accumulated a lot of results. It has a better understanding of the erosive wear of the pipelines, but nowadays the problem caused by pipe erosion is becoming more and more serious, the study of the internal flow of pipes that have been worn for a long period of time has received less 
attention. To the currently popular dredging industry, for example, the concentration of slurry transported is high, the density of the liquid particle is big and the kinds of soil are various, so the erosion wear of the pipes is different in the construction. It is mostly a mixture of sediment and gravel in the dredger pipeline transportation, pipe erosion speed is very fast, which will be one of the important factors to trouble and restrict the development of pipeline transportation technology in the future. Once the pipelines are in the event of damage, it will directly affect the safety and efficient operation of the construction of the dredger, and the slurry leakage will cause environmental pollution. With the national energy-saving and emission-reduction slogan proposed and dredging market competition became increasingly fierce, improving economic efficiency and reducing construction costs will become a big trend. Therefore, the study of pipeline wear law and the exploration of the pipeline side exchange strategy are of great significance for ensuring the safety and reliable operation of dredger, reducing construction costs and the protection of the environment.

\section{Mathematical And Physical Model}

\subsection{Mathematical model}

\subsubsection{Control equations}

The flow of fluid is consistent with the law of conservation, the commonly used conservation laws are: the law of conservation of mass, the law of conservation of momentum, the law of conservation of energy. If the fluid consists of multiple components, and there is interaction between the different mixed components, then the fluid conforms to the law of conservation of components. According to the fluid flow state, we will determine whether to add turbulent transportation equation. The control equation is a mathematical description of these conservation laws. Since the Heat exchange and temperature change in the flow process are not considered in this study, the energy conservation equation is not used.

(1)the equation of conservation of mass

$$
\frac{\partial\left(\mathrm{pu}_{\mathrm{i}} \mathrm{j}\right)}{\partial \mathrm{x}_{\mathrm{i}}}=0
$$

(2)the equation of conservation of momentum

$$
\frac{\mathrm{pD} \& \mathrm{u}_{\mathrm{j}} \mathcal{}}{\mathrm{Dt}}=-\frac{\partial \mathrm{p}}{\partial \mathrm{x}_{\mathrm{j}}}+\mu \frac{\partial^{2} \mathrm{u}_{\mathrm{j}}}{\partial \mathrm{x}_{\mathrm{i}}^{2}}+\mathrm{pf}_{\mathrm{j}}
$$

(3)The turbulence model uses the standard $\kappa-\varepsilon$ equation transportation equation of turbulent kinetic $\kappa$ :

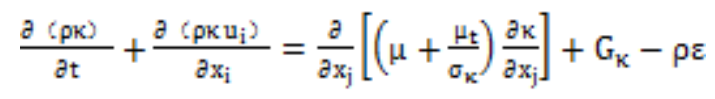

Transportation equation of turbulent dissipation rate $\varepsilon$ :

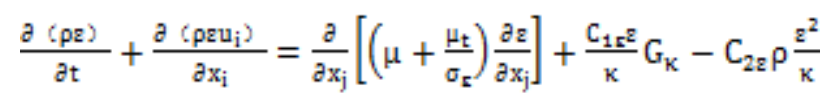

Where turbulence viscosity: $\mu_{\mathrm{t}}=\mathrm{pC}_{\mathrm{\mu}} \frac{\mathrm{K}^{2}}{\mathrm{~g}}$

In the equation, $\mathrm{C}_{1 z}, \mathrm{C}_{2 z}, \mathrm{C}_{\mu}$ are empirical constants, $\sigma_{\mathrm{K}}, \sigma_{z}$ are Prandtl numbers which are corresponds to turbulent kinetic $\kappa$ and turbulent dissipation rate $\varepsilon . \mathrm{G}_{\mathrm{K}}$ is the generation of turbulent kinetic $\kappa$ at average velocity.p is the fluid density. $\mu$ is the dynamic viscosity. $t$ is the thermodynamics temperature. According to the values recommended by Launder and other people and later experimental verification, the model constants can be available in the tables. $\mathrm{C}_{1 z}=1.44, \mathrm{C}_{2 \varepsilon}=1.92$, $\mathrm{C}_{\mathrm{p}}=0.09, \sigma_{\mathrm{K}}=1.0, \sigma_{\mathrm{z}}=1.3$.

\subsubsection{Erosion equations}

Erosive wear in the pipelines is a complex process, the main reason is the collision and friction between the solid particles and the wall in the slurry transmission; the other reason is that the solid 
particles hit against the wall at a certain impacting angle, which will cause the pipe wall scraping damage. Usually we use the erosion rate to measure the degree of wear of solid particles on the inner wall. Here we use the E / CRC erosion model which has the better simulation results to calculate the pipe wear rate, as shown below

$$
\begin{aligned}
& \mathrm{ER}=\mathrm{C}(\mathrm{BH})^{-0.59} \mathrm{~F}_{\mathrm{s}} \mathrm{V}_{\mathrm{p}}^{\mathrm{n}} \mathrm{F}(\theta) \\
& \mathrm{F}(\theta)=\sum_{\mathrm{i}=1}^{5} A_{\mathrm{i}} \theta^{\mathrm{i}}
\end{aligned}
$$

Where ER is the erosion ratio, defined as the amount of mass lost by the wall material due to particle impacts divided by the mass of particles impacting; $\mathrm{BH}$ is the Brinell hardness of the wall material; $F_{s}$ is the particle shape coefficient; $F_{s}=1.0$ for sharp (angular), 0.53 for semi-rounded, or 0.2 for fully rounded sand particles; $V p$ is the particle impact speed in $\mathrm{m} / \mathrm{s} ; \theta$ is the impact angle in radians; $n=2.41$ and $C=2.17 \times 10^{-7}$ are empirical constants. Values of $A_{i}$ for $i=1-5$ are listed below:

Table $1 . \mathrm{I}=1-5$ value

\begin{tabular}{|c|c|c|c|c|}
\hline $\mathrm{A}_{1}$ & $\mathrm{~A}_{2}$ & $\mathrm{~A}_{2}$ & $\mathrm{~A}_{4}$ & $\mathrm{~A}_{5}$ \\
\hline 5.40 & -10.11 & 10.93 & -6.33 & 1.42 \\
\hline
\end{tabular}

\subsection{Physical model}

We select $₫ 100 \mathrm{~mm} \times 10 \mathrm{~mm}$ horizontal straight tube, in order to facilitate the calculation, the length of the pipe is chose to be 3 meters. After the three-dimensional model is established, the mesh is divided in ICEM. As shown in Fig. 1, the number of grid elements is 440895, and the slurry flows in the negative direction of the $y$-axis.

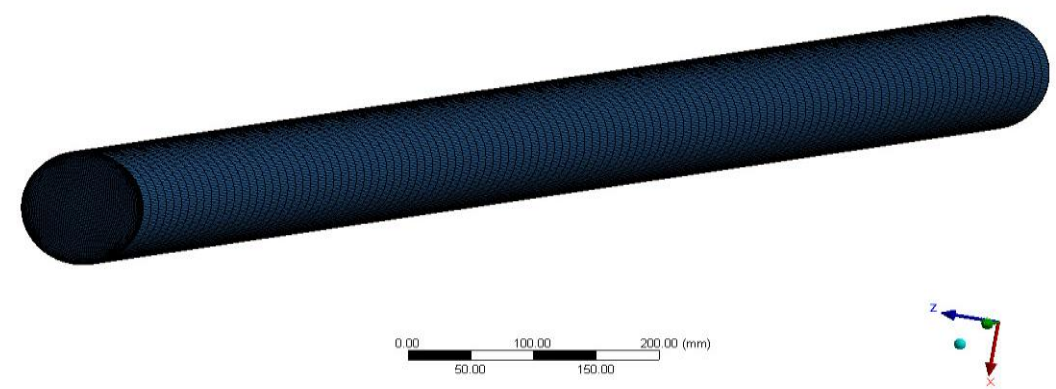

Figure 1. The grid of pipe geometry

\section{Numerical Simulation Results And Analysis}

In the actual production and life, the wear of the pipeline often occurs in the lower part of the pipeline. After a long period of work, there will be the situation of uneven pipe thickness. Often in a region of the pipeline is more serious, and the rupture of a pipeline accident will occur because of the high pressure in the thin area. In the same time, the thickness of other regions still meets the operating standards, which will result in a waste of materials, and seriously affect the pipeline life. Analysis and verification of the main wear parts of the pipeline, while the proposing an effective method to solve the problem, are the starting point and the end result of this study.

Wear is bound to bring the changed shape of the pipe, but due to the complexity of the wear mechanism, the pipe wall wear pattern is difficult to have the rules to follow, so it is almost impossible to completely simulate the pipe wall wear. In the study we will use simplified models to treat the problem. The basic idea is that we firstly simulate the erosion under the condition of the normal circular pipe, and then get the erosion ratio. According to the value of the circumferential erosion ratio of the pipe (as can be seen from Fig. 2), the pipe cross-section should be properly expanded, so that the cross-section will become irregular circular. After that, we will use the new cross-section of the pipe to build the pipe geometry, and then we will get a new physical model. The pipe model we obtain later wear is the worn pipe. 
In Fig. 2 (1), it can be seen that the erosive wear occurs mainly in the middle and lower parts of the pipeline, and the concentrated wear area is shifted to the second half of the pipeline. This is due to the fact that the density of sediment is greater than that of water, and the turbulence of water will have an effect on the sediment movement in the inlet section of pipeline, after that the particles begin to settle down because of the influence of gravity and the erosion wear will concentrate in the lower part of the pipe and the wear zone will be the symmetrical distribution along the circumference, there will be the larger erosion ratio concentrated area within the range of $120^{\circ}$ at the bottom of the pipeline, the erosion ratio of the upper pipe much smaller than that of the lower part, in the simplified model the upper erosion ratio can be ignored. According to the large wear rate range, and in order to make the pipe wear so evenly that in can improve the service life of pipe, this paper proposes two methods to solve the problem, we can make the pipeline rotate at a certain angle which is $180^{\circ}$ or $120^{\circ}$ each time respectively. In accordance with the above establishment method of simplified model, several simplified models of rotated pipe cross section is shown in Fig. 3 (2) (3) (4)

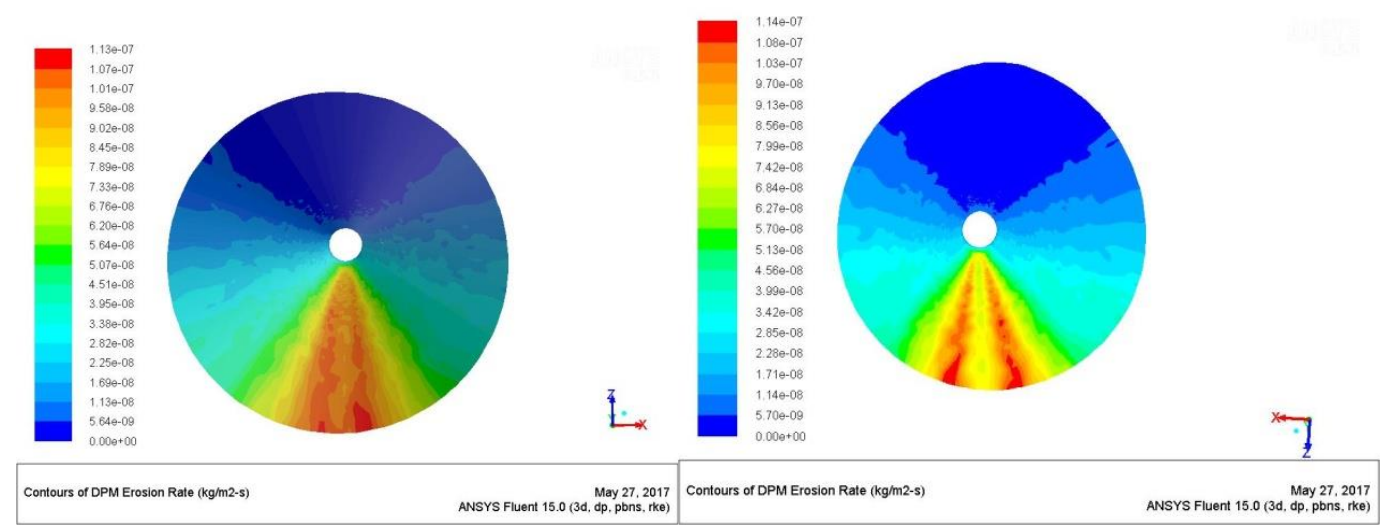

(1) Unworn pipe

(2) rotating at $180^{\circ}$
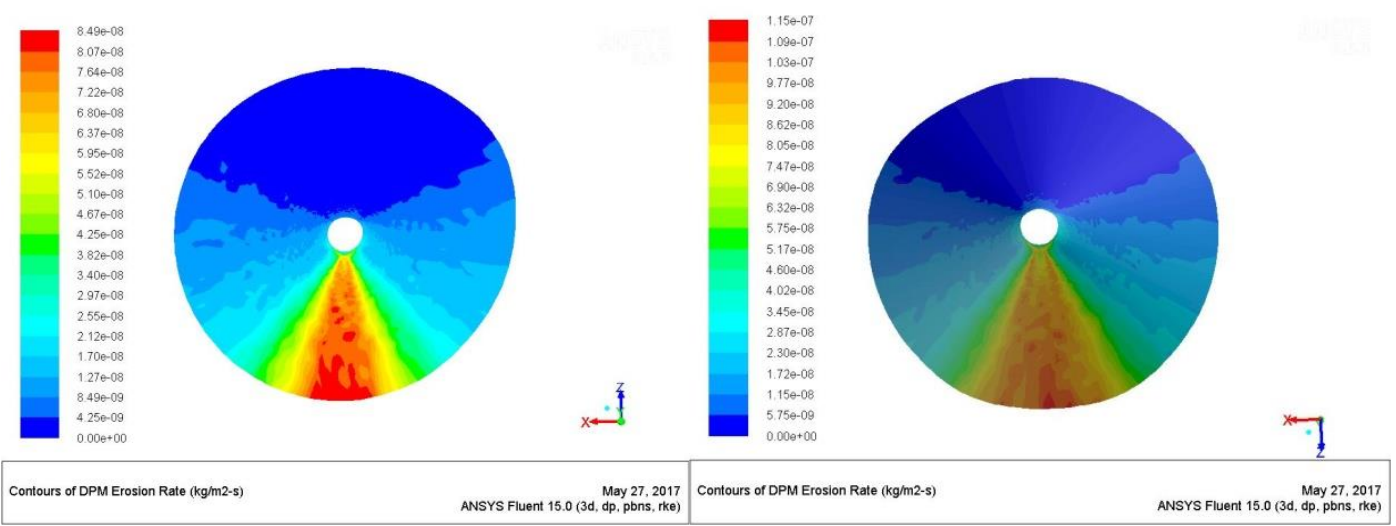

(3) Rotating at $120^{\circ}$ once

(4) rotating at $120^{\circ}$ twice

Figure 2. The erosion ratio of different rotating methods

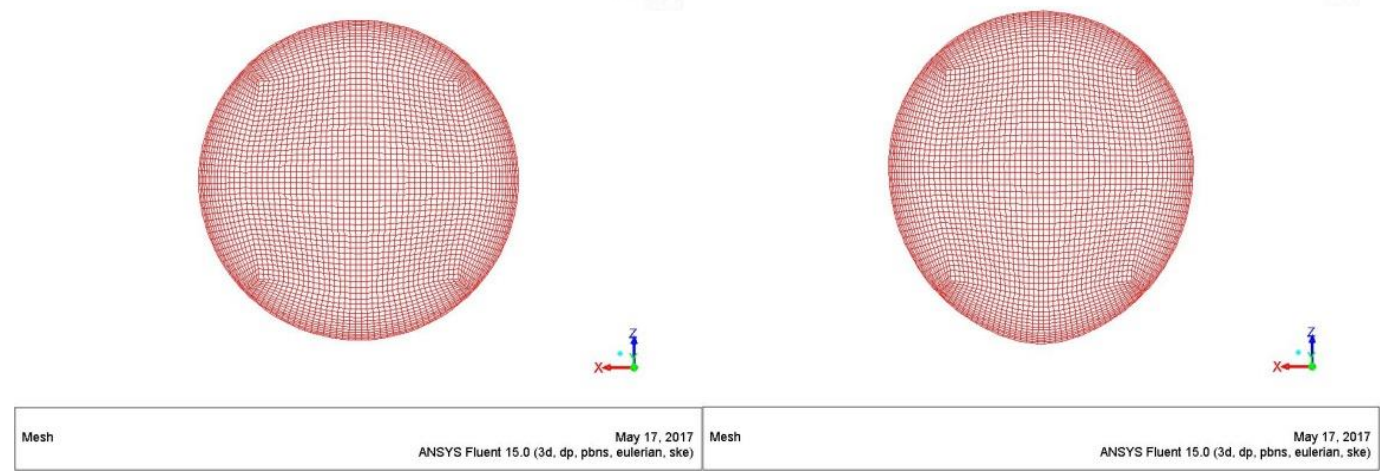

(1) Cross section of unworn pipe (2) cross section of 180 rotating 


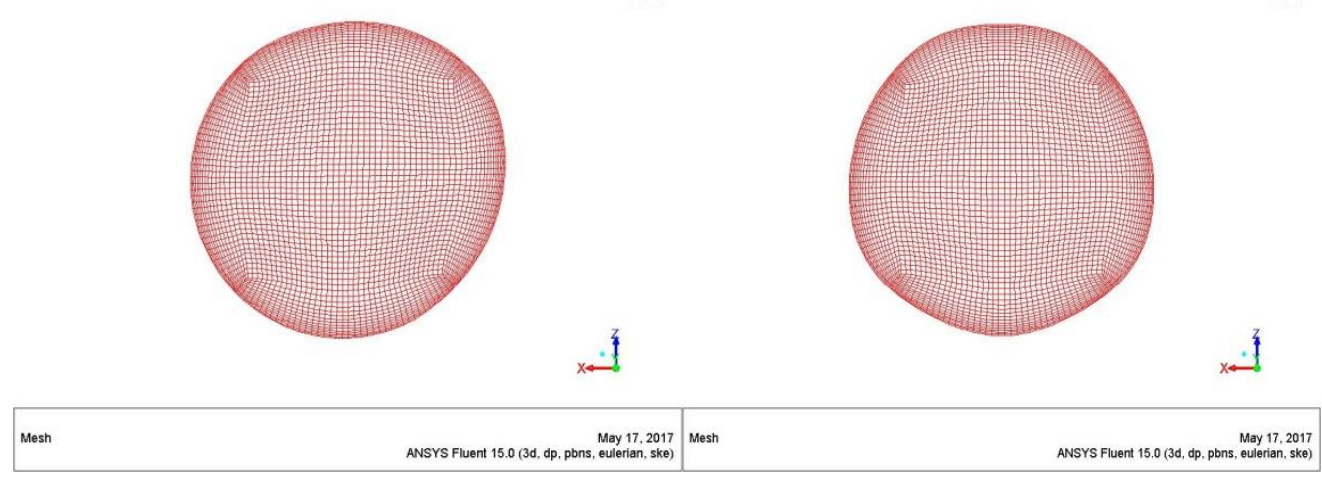

(3) cross section of $120^{\circ}$ rotating once (4) cross section of $180^{\circ}$ rotating twice

Figure 2. The different models of cross - section

\section{Analysis of Pipeline Service Life}

In the process of predicting the service life of pipe, it is necessary to assume that the degree of erosion in a certain range of radians is uniform. The erosion ratio should be chose as the maximum value of the area under actual operating conditions and the pipe should be rotated when the thickness of the zone wears to a certain level. Due to ignoring the influence of pipe thickness variation on wall surface area, so that we can obtain the pipeline erosion thickness of a certain range within 24 hours according to the following formula:

$$
\mathrm{S}_{\mathrm{i}}=8.64 \times 10^{7} \frac{\mathrm{R}_{\text {srasion }}}{\mathrm{p}}
$$

In the equation, $\mathrm{S}_{\mathrm{i}}$ is the average worn thickness of the pipe area $\mathrm{i}$ for one day, $\mathrm{mm}$ : $\mathrm{R}_{\text {erosion }}$ is the erosion ratio, $\mathrm{kg} /\left(\mathrm{m}^{\mathrm{a}} \cdot \mathrm{s}\right) ; \rho$ is the density of the pipe material.

The pipe rotation should meet the principle of effective using and the longest life, in order to achieve this purpose the rotation should meet the following wear law ${ }^{[12]}$ :

For example, the pipe which rotates for $\mathrm{N}$ times should meet the principles:

$$
\begin{aligned}
& \mathrm{h}-\mathrm{S}_{1} \mathrm{~T}_{1}-\mathrm{S}_{2} \mathrm{~T}_{2}-\mathrm{S}_{\mathrm{a}} \mathrm{T}_{\mathrm{a}}-\mathrm{S}_{4} \mathrm{~T}_{4} \cdots \mathrm{S}_{\mathrm{N}+1} \mathrm{~T}_{\mathrm{N}+1} \geq \delta_{\text {min }} \\
& \mathrm{h}-\mathrm{S}_{2} \mathrm{~T}_{1}-\mathrm{S}_{1} \mathrm{~T}_{2}-\mathrm{S}_{2} \mathrm{~T}_{\mathrm{a}}-\mathrm{S}_{\mathrm{a}} \mathrm{T}_{4} \cdots \mathrm{S}_{\mathrm{N}} \mathrm{T}_{\mathrm{N}+1} \geq \delta_{\text {min }} \\
& \mathrm{h}-\mathrm{S}_{\mathrm{a}} \mathrm{T}_{1}-\mathrm{S}_{2} \mathrm{~T}_{2}-\mathrm{S}_{1} \mathrm{~T}_{\mathrm{a}}-\mathrm{S}_{2} \mathrm{~T}_{4} \cdots \mathrm{S}_{\mathrm{N}-1} \mathrm{~T}_{\mathrm{N}+1} \geq \delta_{\text {min }} \\
& \mathrm{h}-\mathrm{S}_{4} \mathrm{~T}_{1}-\mathrm{S}_{\mathrm{a}} \mathrm{T}_{2}-\mathrm{S}_{2} \mathrm{~T}_{\mathrm{a}}-\mathrm{S}_{1} \mathrm{~T}_{4} \cdots \mathrm{S}_{\mathrm{N}-2} \mathrm{~T}_{\mathrm{N}+1} \geq \delta_{\text {min }} \\
& \mathrm{h}-\mathrm{S}_{\mathrm{N}+1} \mathrm{~T}_{1}-\mathrm{S}_{\mathrm{N}} \mathrm{T}_{2}-\mathrm{S}_{\mathrm{N}-1} \mathrm{~T}_{\mathrm{a}} \cdots \mathrm{S}_{1} \mathrm{~T}_{\mathrm{N}+1} \geq \delta_{\text {min }}
\end{aligned}
$$

the longest service life of pipe: : $D=\max \left\{\mathrm{T}_{1}+\mathrm{T}_{2}+\mathrm{T}_{\mathrm{a}}+\cdots+\mathrm{T}_{\mathrm{N}+1}\right\}$. Where $\mathrm{h}$ is the pipe thickness, mm.

In the actual process of construction, once the pipe wall thickness is below the minimum thickness $\delta_{\min }$ of a certain pressure, the rupture of a pipeline accident will occur because of the pressure. Assuming the internal pressure of the pipe is $4 \mathrm{MPa}$, the thickness of the pipe wall corresponding to the three types of steel pipe produced by a company is taken as an example. The specific data are shown in Table 2:

Table 2. Minimum thickness of the three pipes

\begin{tabular}{cccc}
\hline type & $\emptyset 108 \times 10 \mathrm{~mm}$ & $\emptyset 168 \times 10 \mathrm{~mm}$ & $\emptyset 219 \times 10 \mathrm{~mm}$ \\
\hline$\delta_{\min }$ & $4.5 \mathrm{~mm}$ & $5.5 \mathrm{~mm}$ & $7.0 \mathrm{~mm}$ \\
\hline
\end{tabular}

As it can be seen from the table above, when the pipe wears a certain thickness, in most cases the remaining part is more than $1 / 2$ of the original thickness. In other words, when the shape of the inner cross-section of the pipe changes little, the pipeline has been difficult to use normally. However, in order to highlight the pattern of the worn pipeline, and study the change of the erosion ratio in different pipe forms, we will adopt an extreme standard which ignores the minimum thickness of the pipe and regard the time of wearing the pipe wall thickness to zero as its service life. Although the value will be much larger than that in actual situation, but it still can clearly reflect the impact of different pipeline rotation strategy on its service life. 
This study is based on two specific strategies to discuss the extension of pipeline life in specific situations. When the rotation angle is $180^{\circ}$, the pipe is divided into upper and lower parts based on the above-mentioned erosion model, and the maximum erosion ratio is taken as the average erosion ratio in the area. The erosion thickness of the two parts are calculated by the formula (6), the service life of pipe consists of the two parts, which are the time of rotating before and the time of rotating after. When the pipe rotation at an angle of $120^{\circ}$ is carried out, the situation is more complicated. The pipe is divided into three parts. The maximum erosion ratio is taken as the average erosion ratio in the area, and the wear thickness of the three parts is calculated by the formula (6). Then the service life of pipe consists of the three parts, which are the time of rotating before, the time of rotating once at an angle of $120^{\circ}$ and the time of rotating twice at an angle of $120^{\circ}$. The specific erosion ratio can be available from Fig.2 (2) (3) (4). It is worth noting that, in the case of different rotations, although the wear area is slightly different, the maximum erosion ratio is approximately the same in numerical values, probably because the grooves under the scale do not aggravate turbulence because the pipe inner wall is still covered by the boundary layer, so the shape of the erosion pipe does not affect the flow of the tube too much. In other words, the parameters in formula (5) do not change a lot, so the value of the erosion ratio is basically the same.

The mentioned above pipeline rotation strategy is based on that the pipe wall wear $6 \mathrm{~mm}$, and the service life of pipe is regarded as the time of wearing the pipe wall thickness to zero.

In the calculation of the service life, we should pay special attention to the point that the erosion of pipeline in the course of the operation not only occurs in the bottom of the wear area, the erosion of other parts can not be ignored. In order to get the service life of pipe, we should ensure that other parts have not been worn out to prevent the rupture of a pipeline accident occurs at the top or the side of the pipeline firstly. Such as the $180^{\circ}$ rotation strategy, on the basis of that the lower part of the tube are worn out, there should be the remaining margin at the upper part. In the $180^{\circ}$ rotation strategy, we will ensure that the two sides of the pipeline will not wear out firstly.

It is estimated that in the case of simulated situation, the service life of irrational pipe is only 2770 days, but the life can be up to 4400 days in the case of the above-mentioned rotation at $180^{\circ}$, and in the case of the rotation at $120^{\circ}$, If only rotated once, the service life can reach 4754 days; if rotated twice, then the service life can be increased to 5670 days, the values are shown in Table 2 . It can be seen that the smaller angle that the pipes rotate at, the shorter cycle of each rotation, the corresponding pipeline life will be more greatly improved. This is due to the frequent rotation of the pipe can make the inner wear evenly, to maximize the performance of the wall material. However, due to the actual process of construction, there are so many large diameter and heavy pipe that it is difficult to rotate, and it is impossible to frequently rotate the pipes. In the same time, it can be seen in Figure 3 that the serious erosion areas concentrate in $120^{\circ}$ of the lower part of the pipeline. On the other hand, it is considered that the rotation angle is $120^{\circ}$ and the number of rotations is twice, which can improve the service life of the pipeline to a large extent.

Table 3. Pipeline life of different pipe rotation

\begin{tabular}{ccccc}
\hline pipe rotation & irrational pipe & rotating at $180^{\circ}$ & rotating at $120^{\circ}$ once & rotating at $120^{\circ}$ twice \\
\hline pipeline life $/ \mathrm{d}$ & 2770 & 4400 & 4754 & 5670 \\
\hline
\end{tabular}

\section{Conclusion}

(1) After a period of operation, the worn seriously area concentrate in $120^{\circ}$ of the lower part of the pipeline, and distributed symmetrically in the circumferential direction, and the concentrated wear area is shifted to the second half of the pipeline. In the case of changing only the cross-sectional shape of the inner circumference of the pipe, the concentrated wear area of the pipe does not move and the value of erosion ratio does not change too much either.

(2) pipe rotation will be carried out after a period of time, which can exponentially improve the service life of the pipeline, and with the angle of each rotation decreases, and the number of rotation increases, the extension of the service life is also more obvious. According to the distribution 
characteristics of the erosive area, a method of rotating the pipeline is put forward, which can double the service life of the straight pipe. Although there are some differences with the actual situation, it is an effective method to prolong the life of the pipeline.

\section{Acknowledgments}

*Corresponding auther.Tel.+8613237181778

E-mail: bearmos@163.com

\section{References}

[1]. Lin N. Erosion Study on Typical Fittings in High Pressure Natural Gas Pipelines [D].Beijing: Beijing Jiaotong University, 2013. (In Chinese)

[2]. Chen C P, Wood P E.A turbulence closure model for dilute gas-particle flows.The Canadian Journal of Chemical Engineering, 1985, 63 (3):349- 360.

[3]. LEE B E, FLETCHER CA J, BEHNIA M. Computational study of solid particle erosion for a single tube in crossflow. [J].Wear, 2000, 240:95- 99.

[4]. Oka Y I, Yoshida T. Pracitical estimation of erosion damage caused by solid particle impact: Part2: Mechanical properties of materials directly associated with erosion damage [J].Wear, 2005, 259 (1):102-109.

[5]. Oka Y I, Okamura T, Practical estimation of erosion damage caused by solid particle impact: Part1: Mechanical properties of materials directly associated with erosion damage [J].Wear, 2005, 259 (1):95-101.

[6]. Zhang Y, Reutrterfors E P, Mclaury B S, et al.Comparison of computed and Measured particle velocities and erosion in water and air flows. [J]. Wear.2007, 263 (1): 330-338.

[7]. Sun H J, Ou G F, Xue D H. Numerical Investigation of Erosion for Multiphase Flow Elbow in Coal Liquefaction [J]. Fluid Machinery. 2013, 41: 45-47. (In Chinese)

[8]. Fu L, Gao B J. Numerical Simulation of the Flow Field and Wear Prediction of the Elbows of Coal Oil Slurry Transporting Pipelines [J]. Chemical Engineering \& Machinery. 2009, 36(5):463-466. (In Chinese)

[9]. Zhang S F, Cao H M, Liu Y. Numerical Simulation of Liquid-solid Two-phase Flow and Erosion-collision in a Syphon. [J]. JOURNAL OF HEBEI UNIVERSITY OF TECHNOLOGY. 2008, 37 (3):48-54. (In Chinese)

[10]. Ma Y, Ren J, Li Y D. Development of research on erosion of materials [J]. Journal of Lanzhou University of Technology, 2005, 31 (1):21-25. (In Chinese)

[11]. Mao J R, Liu C W, Xiang X W. Effect of Secondary Flow on Erosion from Solid Particles in $90^{\circ}$ Curved Duct of Quadrate Section. JOURNAL OF XI'AN JIAOTONG UNIVERSITY, 2004, 38 (7): 746- 749. (In Chinese)

[12]. Liu P K. Analysis on pipeline abrasion based on FLUENT and study on side exchange laws. [J].MINING \& PROCESSING EQUIPMENT, 2016, : 35-38. (In Chinese) 